\title{
Respiratory mutant and liquid holding recovery inhibition in yeast cells
}

\author{
E.S. Evstratova* ${ }^{*}$ V.G. Petin, M.D. Pronkevich \\ Tsyb Medical Radiological Research Centre, Branch of the National Medical Research Radiological Centre of the \\ Ministry of Health of the Russian Federation, 249036 Obninsk, Russia
}

\section{- Original article}

\author{
*Corresponding author: \\ Dr. Ekaterina S. Evstratova, \\ Fax: +4843993052 \\ E-mail: ekevs7240@mail.ru \\ Revised: May 2016 \\ Accepted: July 2016 \\ Int. J. Radiat. Res., April 2017; \\ 15(2): 129-139 \\ DOI: $10.18869 /$ acadpub.ijrr.15.2.129
}

\begin{abstract}
Background: Cell ability to recover from radiation damage is of great relevance in cancer treatment. It is often believed that the inhibition of cell ability to the liquid holding recovery (LHR) may be an indicator of the overall suppression of cell ability to recover from potentially lethal radiation damage. However, the literature contains no experimental evidence whether the LHR inhibition may always serve as marker of the significant increase in cell sensitivity to damaging agents. Materials and Methods: In experiments described here the yeast cells were used as a model for eukaryotic cells. The dose-response curves and recovery kinetics were determined by colony assay after simultaneous treatment of heat with ionizing or UV radiations as well as after the simultaneous action of ionizing radiation and cisplatin. The cell survival was estimated by both microscopic method and colony forming ability. Results: It is demonstrated that the recovery may take place on nutrient media. The complete inhibition of cell recovery after simultaneous heat treatment with ionizing radiation or UV light is accompanied with the significant increase in cell sensitivity to these agents, the actual increase being more appreciable than that expected after the inhibition of the LHR only. This rule is not universal as it was demonstrated for diploid yeast cells exposed to ionizing radiation and cisplatin. Conclusion: The LHR takes place on nutrient media during the delay of the first postirradiation division. The LHR inhibition may not always indicate the suppression of other dark recovery processes and the corresponding increase in cell radiosensitivity.
\end{abstract}

Keywords: Yeast cells, ionizing radiation, UV light, hyperthermia, cisplatin, liquidholding recovery

\section{INTRODUCTION}

It is believed that DNA repair is one of the most important factors in determining cellular sensitivity to ionizing radiation and some other cytotoxic agents (1, 2). Enzymatic processes taking part in cell recovery from radiation-induced DNA damage are known to define the ultimate biological effects produced by ionizing radiation. Many tumors are known to become resistant to ionizing radiation due to the increased efficiency of DNA repair $(2,3)$. The inhibition of cell recovery and DNA double strand breaks repair by chemicals is expressed by a decreased recovery rate and a lesser extent of recovery. It is obvious that these observations may be caused by the following reasons: (i) the damage or impairment of the recovery process itself, (ii) the increase in the portion of irreversible damage, (iii) both of these reasons. In our recent publications $(4,5)$, it was shown the inhibition of cell recovery from potentially lethal damage in yeast cells exposed to simultaneous action of ionizing radiation with various physical or chemical agents are realized mainly through the enhanced yield of irreversible damage whereas the probability of recovery per unit time was not damaged or impaired. The 
decrease in the cell ability to recover from radiation damage would be of great relevance in cancer treatment (6). Several physical agents and a lot of chemicals are known to enhance the inactivation effect of ionizing radiation for various cellular systems $(6-10)$. It is assumed that radio sensitization may be brought about by the inhibition of DNA repair including the liquid holding recovery (LHR) from potentially lethal radiation damage. The LHR is manifested by an increased colony-forming ability when irradiated cells are held in non-nutrient medium before being placed on rich medium $(11,12)$. Regarding this radiation effect, it is worth to mention that it has been reported long time ago and mentioned in recent publication (1) that keeping irradiated cells in sub-optimal environment condition also resulted in increase of cell survival. It has been suggested this effect was due to DNA repair improvement in this condition (1). It is known that the recovery processes are ceased after the completion of the first division of irradiated cells (11). It is not excluded that sub-optimal environment condition resulted in increase of cell survival due to enhanced duration of recovery because of a slowdown of cell division. Therefore one of the aim of this paper is to present new experimental data demonstrating that increase in the duration of LHR on sub-optimal condition can result in an increased cell survival.

The process of LHR is often considered to be an indicator of other dark repairs. This type of cell recovery is known to occur often and was demonstrated in cells of various origins and takes place during the delay of the first post-irradiation cell division $(11,12)$. It is often believed, without serious argumentation that the inhibition of cell ability to the LHR may serve as an indicator of the overall suppression of cell ability to recover from radiation damage (1, 8-10, 13). Although there are considerable interests in combining ionizing radiation with physical and chemical agents in order to improve tumor treatment, there were no reports in the literature in regard with the magnitude of the expected increase in radiosensitivity, when such a recovery is suppressed. Therefore the second aim of this paper was to ascertain whether or not the LHR inhibition may always serve as an indicator of significant increase in cell sensitivity to damaging agents due to inhibition of other dark repair systems.

\section{MATERIALS AND METHOD}

The yeasts Saccharomyces ellipsoideus (diploid strains Megry 139-B and Megry 39-2) and Saccharomyces cerevisiae (strains XS800, diploid; S288C, haploid) were used for these work. To attain stationary phase of growth, cells were incubated before irradiation on a solid complete nutrient agar during 4-10 days. The duration of cultivation was determined by the cessation of cell budding. The budding cell component in the experimental suspension was found to be less than 2 percent. Final suspensions prepared for irradiation and heat treatment contained approximately $10^{6}$ yeast cells per ml. Such a cell population consisted of single cells with a rather homogeneous cell size distribution. The exposed cell suspension was adjusted to $\mathrm{pH}$ 7.0. Radiobiological characteristics of diploid strains (XS800 and Megry 139-B) are well studied $(4,11)$, both strains are capable of the LHR. Diploid strain Megry 39-2 is respiratory-deficient and incapable of LHR due to cytoplasmic mutation (12). Haploid strain S288C is also incapable of LHR since this type of recovery is realized through the repair of DNA double-strand breaks, which requires two homologous DNA duplexes (14).

Aliquots with $10^{6}$ yeast cells $/ \mathrm{ml}$ in a glass tube were exposed to graded doses of ${ }^{60} \mathrm{Co}$ $\gamma$-rays. The $\gamma$-ray dose-rates, estimated by ferrous sulfate dosimetry and by a Siemens ionization chamber, were 10 and $23 \mathrm{~Gy} / \mathrm{min}$, - irradiation of S. ellipsoideus and S. cerevisiae strains respectively. The following heating method was used alone or combined with $\gamma$-rays: $0.1 \mathrm{ml}$ of cell suspension (about $5 \times 10^{7}$ cells) at room temperature was placed into 4.9 $\mathrm{ml}$ of sterile water warmed to a required temperature in a water bath beforehand. Cell suspension $\left(1.5 \mathrm{ml}, 10^{6}\right.$ cells $\left./ \mathrm{ml}\right)$ in an open quartz vessel was irradiated with germicidal 
lamp that emitted predominantly UV light of a wavelength of $254 \mathrm{~nm}$ at a fluence rate of $1.5 \mathrm{~W} /$ $\mathrm{m}^{2}$ at different temperatures. The fluence rate was measured with a germicidal meter (General Electric Co. Fairfield, CT). Slightly different heating method was used alone or combined with UV light: $0.1 \mathrm{ml}$ of cell suspension at room temperature (about $1.5 \times 10^{6}$ cells) was placed into $1.4 \mathrm{ml}$ of sterile water preheated to a required temperature. The final volume and concentration of the treated cells were $1.5 \mathrm{ml}$ and $10^{6}$ cells $/ \mathrm{ml}$. For the simultaneous treatment of heat with ionizing radiation or UV light, the time interval between the introduction of the cells into the preheated water and the beginning of exposures was about $0.1 \mathrm{~min}$, which was significantly less than the total treatment time. At the end of the treatment, the samples were rapidly cooled to room temperature. To avoid photoreactivation, the UV exposure, dilution and other procedures were performed under a red ambient light, while the post-irradiation incubation was carried out under dark conditions.

To observe recovery kinetics, a part of the irradiated cell suspension was placed into conditions promoting to the LHR $\left(30^{\circ} \mathrm{C}\right.$ without constant agitation) and their colony forming ability was estimated as a function of storage time. To prove the existence of the LHR on nutrient medium we used microscopic method after $24 \mathrm{~h}$ incubation of irradiated cells on a nutrient media at $30^{\circ} \mathrm{C}$. Colonies containing greater than 50 cells were counted to assess survival. Using this method, in experiments with diploid yeast capable of the LHR (strains Megry 139-B and XS800) we estimated cell viability for the whole irradiated cell population and among two sub-populations: forming the bud before $3.5 \mathrm{~h}$ incubation on nutrient media ( $25 \%$ of budding cells) and not beginning to bud after $6 \mathrm{~h}$ incubation (75\% of budding cells). In experiments with diploid strain 39-2 and haploid strain S288C incapable of the LHR we estimated cell viability also for the whole irradiated cell population and among two other sub-populations: forming the bud before $6.0 \mathrm{~h}$ incubation on nutrient media (25\% of budding cells) and not beginning to bud after $9.5 \mathrm{~h}$ incubation (75\% of budding cells). Such a difference in the time of observation was due to different rates of reproduction of these yeast strains.

Cisplatin is a chemotherapy drug which is used to treat cancer in combination with exposure to ionizing radiation or hyperthermia. In our experiments, cisplatin ("Veropharm") was added in diploid yeast cell suspension (strain XS800) in various concentration - $0.002,0.01$ and $0.02 \mathrm{mg} / \mathrm{ml}$. The drug was present in cell suspension for $1 \mathrm{~h}$ at $30^{\circ} \mathrm{C}$ before exposure, during irradiation at room temperature and during the LHR at $30^{\circ} \mathrm{C}$.

Immediately after treatments and after various storage time of LHR, a known number of cells were placed on nutrient agar in such a manner that 50-200 colonies per dish would be formed by the surviving yeast cells. Colonies were scored when they reached a suitable size after 5-7 days of incubation at $30^{\circ} \mathrm{C}$. Cultures were grown and maintained on yeast extract $(1 \%)$, peptone $(1 \%)$, and glucose $(2 \%)$ medium, solidified with agar $(2 \%)$. The plating efficiency of untreated cells was close to $100 \%$. Colony-forming ability was used as the criterion for survival. All experimental series were repeated three to five times. Error bars in all figures derived from inter-experimental variations. Data are expressed as the mean values calculated from at least three independent experiments. Curves were fitted to the data points by eye. Other details of materials and methods can be found in our previous papers ${ }^{(15-17) .}$

\section{RESULTS}

Table 1 summarizes our experimental results concerning the survival of diploid yeast cells (strains Megry 139-B and XS800) capable of the LHR and budding at different times after irradiation. The cells were irradiated at a dose of 500 Gy. The viability for the whole cell population was about $25 \%$. It is obvious that the later irradiated cells began budding, the higher will their survival become. This effect may be due to the various duration of the LHR occurring

Int. J. Radiat. Res., Vol. 15 No. 2, April 2017 
on nutrient media. This suggestion agrees with the observation that the opposite situation is observed after complete LHR (48 hr). In this case, to achieve the same viability (about 25\%) yeast cells were irradiated at a dose of $1500 \mathrm{~Gy}$.

An additional argument in favor of the explicated point of view is the data obtained for respiratory mutant cells (strain Megri 39-2, 200 Gy) and haploid cells (strain S288C, $100 \mathrm{~Gy}$ ) incapable of the LHR (table 2). The cell viability for the whole cell population was about $30 \%$, while the cell survival of these strains budding on nutrient media before $6.0 \mathrm{~h}$ was 37 and $31 \%$ while for cells budding later $9.5 \mathrm{~h}$ their survival was 25 and 15\% (table 2). This means that cell viability was greater for cells that previously enter mitosis.

Thus, the main point which emerges from these studies is that the process of cell recovery from radiation damage can occur on nutrient medium and thereby results in the increase of cell resistance to ionizing radiation.

Figure 1 exhibits survival curves for

Table 1. The survival of diploid yeast cells capable of the LHR and budding at different times after irradiation.

\begin{tabular}{|c|c|c|c|}
\hline \multirow{2}{*}{ Strain } & \multirow{2}{*}{ Time of the bud formation, hr } & \multicolumn{2}{|c|}{ Cell survival, \% } \\
\cline { 3 - 4 } & & Immediately after irradiation, 500 Gy & After LHR during 48 hr, 1500 Gy \\
\hline \multirow{2}{*}{ Megry 139-B } & Before 3.5 & 9 & 34 \\
\cline { 2 - 4 } & After 6.0 & 38 & 4 \\
\hline \multirow{2}{*}{ XS800 } & Before 3.5 & 14 & 44 \\
\cline { 2 - 4 } & After 6.0 & 41 & 10 \\
\hline
\end{tabular}

Table 2. The survival of diploid (strain Megri 39-2) and haploid (strain S288C) yeast cells incapable of the LHR and budding at different times after irradiation.

\begin{tabular}{|c|c|c|c|}
\hline \multirow{2}{*}{ Srain } & \multirow{2}{*}{ Dose, Gy } & \multirow{2}{*}{ Time of the bud formation, $\mathrm{hr}$} & Cell survival, $\%$ \\
\hline & & & Immediately after irradiation \\
\hline \multirow{2}{*}{ Megry 39-2 } & \multirow{2}{*}{200} & Before 6.0 & 37 \\
\hline & & After 9.5 & 25 \\
\hline \multirow{2}{*}{ S288C } & \multirow{2}{*}{100} & Before 4.5 & 31 \\
\hline & & After 7.0 & 15 \\
\hline
\end{tabular}

S. ellipsoideus diploid yeast cells obtained in experiments with strains Megry 139-B capable of the LHR (curve 1) and Megry 39-2 incapable of such kind of recovery (curve 2). Curve 3 reflects the expected survival curve for Megry 139-B cells if they would not be able to the LHR on nutrient media. It was calculated by means of mathematical approach developed before (12). It was shown in the cited paper the effect was dose modifying, i.e. survival curve 1 can be superimposed with curve 3 by changing the dose scale by a constant factor. This dose modifying factor (DMF) due to the LHR on the nutrient media was found to be of 1.42 . This means the LHR occurring on the nutrient media before the fixation of radiation damage results in a decrease of cell radiosensitivity by a factor of 1.42. The data indicate that at doses Int. J. Radiat. Res., Vol. 15 No. 2, April 2017 corresponding to the exponential part of the survival curve the calculated curve almost coincides with the survival curve of yeast Megry 39-2 while in the low dose region it is slightly higher. The latter difference may be due to the fact that at low dose region cells may be recovered more efficiently for example due to the repair of sub-lethal radiation damage responsible for the shoulder of the survival curves (1).

It is of interest to apply this method to establish whether the LHR inhibition may always serve as an indicator of significant increase in radiosensitivity due to the overall suppressing of cell ability to recover from radiation damage. This hypothesis is often referred to or only implied in many publications related with the search of chemical or physical 
agents enhancing cell sensitivity to ionizing radiation $(2,6-10,18,19)$. For example, hyperthermia is known to increase the inactivation effect of ionizing radiation or UV light on various cellular systems. A number of mechanisms may be involved in sensitization, prominent among which is the impairment of DNA repair processes $(18,20)$. It is generally assumed that thermal radiosensitization on a cellular level may be displayed by the inhibition of sublethal and potentially lethal damage recovery (7-10). Some data indicated that both repair inhibition and particular lesion types were required for lethal synergism between heat and radiation ${ }^{(5)}$. Therefore, it would be of interest to compare the degree of thermal sensitization of cells subjected simultaneously to heat and ionizing radiation with that expected after the inhibition of cell ability to the LHR.

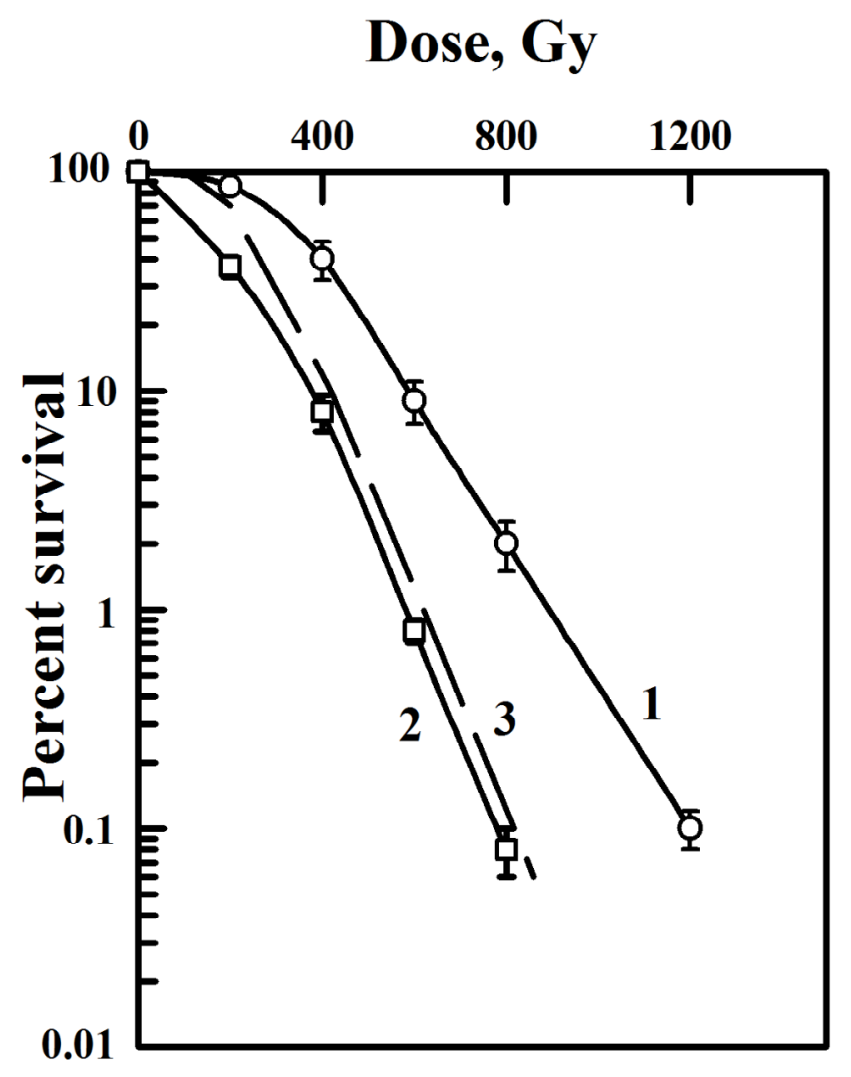

Figure 1. Survival curves of diploid yeast cells S. ellipsoideus strains Megry 139-B (curve 1), Megry 39-2 (curve 2) and the expected survival curve of Megry 139-B in the absence of the LHR from potentially lethal damage on nutrient medium (curve 3).

The most detailed data concerning this problem have been obtained for yeast cells, a part of this findings has been published previously $(4,5,15)$. However, these publications did not concern the question, whether or not the LHR inhibition may serve as an indicator of the significant increase in cell radiosensitivity due to the overall suppressing of cell ability to recover from radiation damage. Figure 2 shows the 133 averaged data of our previously published results obtained with diploid yeast cells. Figure 2A displays survival curves of cells subjected to simultaneous heat and ionizing radiation treatment. Two effects are apparent: a reduction in the $D_{0}$ in terminal high dose region of radiation survival curve, and a decrease in the shoulder region $\left(D_{q}\right)$ of the survival curve at lower radiation dose. It is obvious that the

Int. J. Radiat. Res., Vol. 15 No. 2, April 2017 
increase in the exposure temperature resulted in an increase in cell radiosensitivity (curves $3-5)$. A comparison in the ability of yeast cells to the LHR carried out at approximately equal levels of survival (i.e. at equal amounts of lethal lesions) is shown in Fig. 2B. The data imply that both the rate and the extent of recovery decreased with increasing temperature at which the irradiation occurred. No LHR was observed after irradiation at $55^{\circ} \mathrm{C}$. The dashed line refers the expected survival curve for Megry 139-B cells if they would not be able to the LHR on the nutrient media. This curve is identical to curve 3 presented in figure 1 for respiratory mutant cells incapable of LHR. It can be seen that the actually observed increase in radiosensitivity is much higher than that expected due to the suppression of the LHR. This means the full inhibition of the LHR may serve as an indicator of the significant increase in cell radiosensitivity.

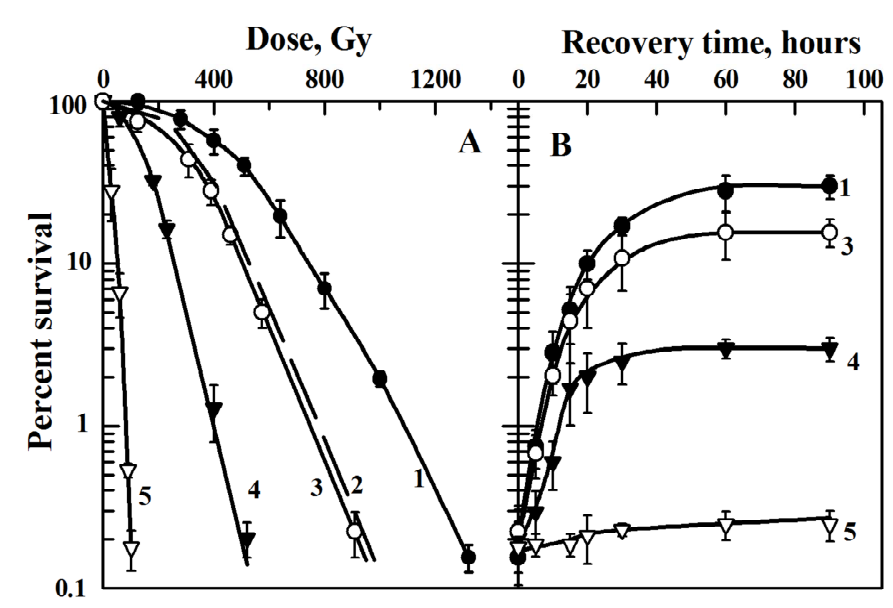

Figure 2. Survival curves (A) and LHR kinetics (B) of diploid yeast cells S. ellipsoideus strain Megry 139-B. Cells were exposed to ionizing radiation at various temperatures: $20,45,50$ and $55^{\circ} \mathrm{C}$ (curves $1,3,4$ and 5 respectively). Irradiated cells were plated immediately after irradiation (A) or after various LHR times (B). Dashed line (curve 2 ) denotes the expected survival curve of

Megry 139-B exposed at room temperature in the absence of LHR from potentially lethal damage on nutrient medium.

Whereas considerable knowledge about repair processes in UV-irradiated cells has been gained during past decades (21), the situation is far less clear for the combined action of UV light with other inactivating factors. It seems widely accepted now that the synergistic interaction of the UV light combined with other agents is displayed by decreased repair rates at molecular and cellular levels $(16,21)$. It is not clear, however, whether or not the LHR inhibition may serve as an indicator of the significant increase in cell sensitivity to UV light. Therefore, it is of interest to compare the degree of thermal sensitization of cells subjected to heat and UV radiation with yeast cells. Fig. 3 shows the averaged data of our previously published results $(4,16,19)$. The survival curves of diploid yeast cells (S. cerevisiae, strain XS800) subjected to simultaneous treatment with heat and UV radiation are presented at figure $3 \mathrm{~A}$. Curve 1 exhibits the survival curve obtained after the cell exposure with UV light applied alone (at room temperature). The increase in the exposure temperatures up to 53,55 and $56^{\circ} \mathrm{C}$ (curves $3-5)$ resulted in the significant increase in cell UV sensitivity as shown by both the increase in the slope and the decrease in the extrapolation number. Finally, the survival curve became almost exponential at $57^{\circ} \mathrm{C}$ (curve 6). Both the increase in the slope and the decrease in the extrapolation number with the exposure temperature increase can be considered as an evidence of the recovery processes participation in the heat sensitization. This suggestion is supported by the data indicating the luck of the synergistic interaction of heat and UV light in the UV sensitive ( $\mathrm{rad} 18 / \mathrm{rad} 18$ ) yeast mutant (16). That is why it is of interest to study the effect of hyperthermia applied during the UV light irradiation on the kinetics of the LHR of yeast cells. 
The results are shown in figure $3 \mathrm{~B}$ where the survival of diploid yeast cells is depicted in the dependence of the LHR time. It is apparent that both the slope and the plateau of the recovery curves depend on the exposure temperature. This means that both the rate and the extent of recovery are decreased with increase in the temperature at which the UV illumination occurred. No LHR was observed after irradiation at $57^{\circ} \mathrm{C}$. The dashed line (figure $3 \mathrm{~A}$ ) reflects the expected survival curve for XS800 cells if they would not be able to the LHR on the nutrient media. It is evident from this data that the actually observed increase in cell sensitivity to UV light is much higher than that expected due to the suppression only the LHR. This means that the full inhibition of the LHR may serve as an indicator of a significant increase in cell sensitivity to UV exposure due to either interference with other repair mechanisms responsible for UV cell resistance, or enhanced expression of lethal damage, for example due to the synergistic interaction of heat and UV radiation (21).

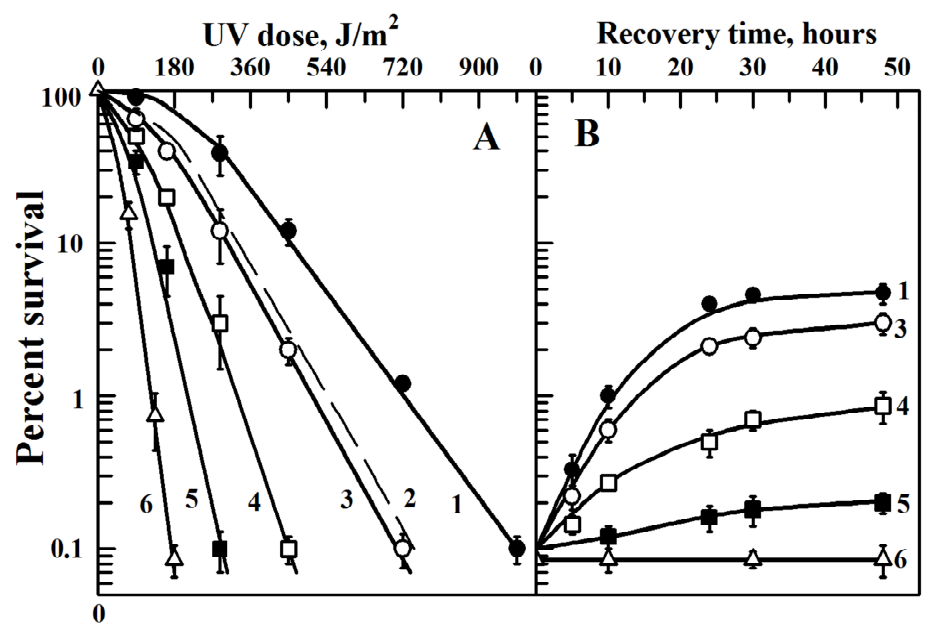

Figure 3. Survival curves (A) and LHR kinetics (B) of diploid yeast cells S. cerevisiae strain XS800. Cells were exposed to UV light at various temperatures: $20,53,55,56$ and $57^{\circ} \mathrm{C}$ (curves $1,3,4,5$ and 6 respectively). Irradiated cells were plated immediately after irradiation (A) or after various recovery times (B). Dashed line (curve 2) denotes the expected survival curve of XS800 exposed at room temperature in the absence of LHR from potentially lethal damage on nutrient medium.

In addition, we studied the effect of the simultaneous action of ionizing radiation and cisplatin on the radiosensitivity and the LHR of diploid yeast cells. Cisplatin is a cytotoxic drug used in cancer chemotherapy (13). Figure 4 shows the dependence of diploid yeast cell survival on the dose of ionizing radiation (figure 4A) and the duration of the LHR (figure 4B). Cells were exposed to radiation without cisplatin and placed on nutrient agar immediately after irradiation and after different time of recovery (curves 1). The drug was present in cell suspension for $1 \mathrm{~h}$ at $30^{\circ} \mathrm{C}$ before exposure, during irradiation at room temperature and during the LHR at $30{ }^{\circ} \mathrm{C}$. Cisplatin was added in diploid yeast cell suspension in various concentration 0.002, 0.01 and $0.02 \mathrm{mg} / \mathrm{ml}$ (curves 2-4), the lower concentration being sufficient to give the highest sensitization. An entirely different pattern was found for cells that undergo LHR in the presence of various concentration of drug. The increase in cisplatin concentration resulted in the progressive decrease of cell ability to the LHR. The dashed line in figure 4A shows the expected survival curve for XS800 cells if they would not be able to the LHR on the nutrient media. These data indicate that the observed increase in radiosensitivity after the combined action of ionizing radiation and cisplatin does not exceed that expected due to the suppression of the LHR and therefore the complete inhibition of the LHR does not always reflect the full inhibition of other repair systems.

Int. J. Radiat. Res., Vol. 15 No. 2, April 2017 


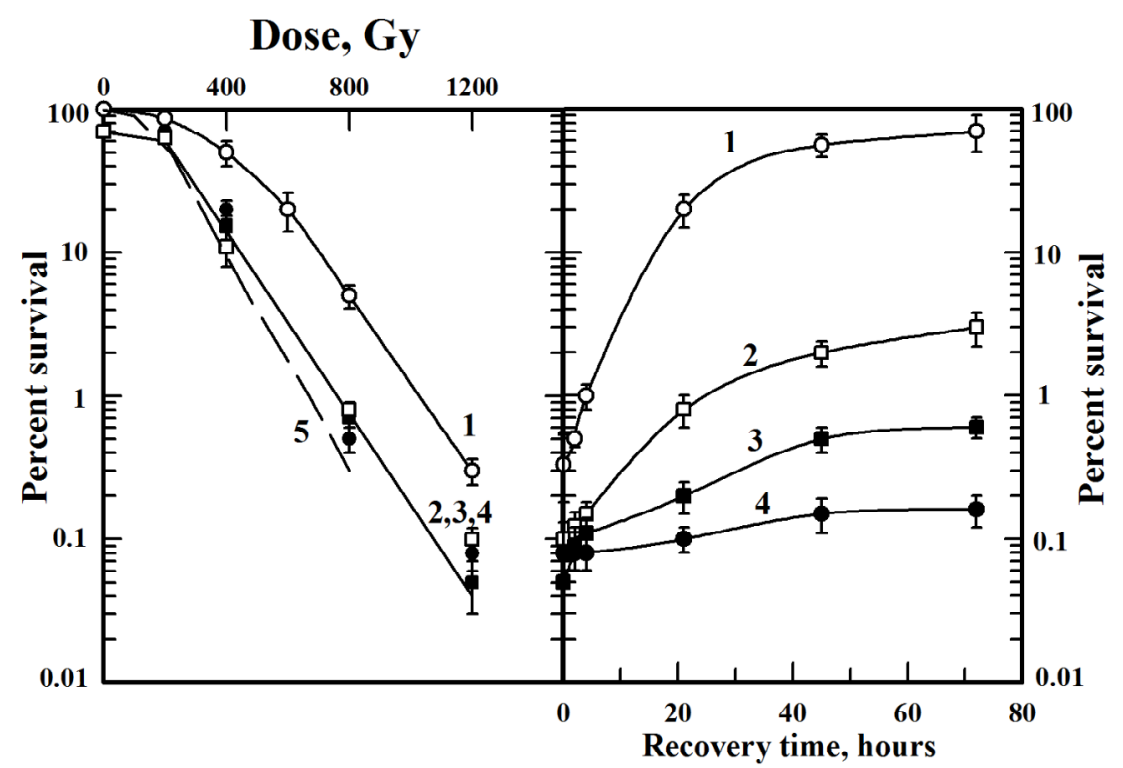

Figure 4. Survival curves (A) and LHR kinetics (B) of diploid yeast cells S. cerevisiae strain XS800. Cells were exposed to ionizing radiation alone (room temperature, curve 1) or combined with various concentration of cisplatin: $0.002,0.01 \mathrm{and} 0.02 \mathrm{mg} / \mathrm{ml}$ (curves 2, 3 and 4, open squares, closed squares and closed circles respectively). Irradiated cells were plated immediately after irradiation (A) or after various LHR times (B). Dashed line (curve 5) denotes the expected survival curve of XS800 exposed at room temperature in the absence of LHR on nutrient medium.

\section{DISCUSSION}

The main purposes of the experiments described here were to present new experimental data supporting the idea that the LHR can occur on nutrient medium after irradiation and to ascertain whether or not the inhibition of the LHR may serve as an indicator of the significant impairment of other dark repair process and thereby to result in an increase in cell sensitivity to ionizing radiation. To accomplish these tasks, new experimental data demonstrating the reality of the LHR on nutrient medium have been obtained. The survival of irradiated cells capable of the LHR was shown to be the greater, the later they began budding after irradiation providing a longer time for recovery. On the contrary, for irradiated cells incapable of LHR or accomplished this process, the pattern was quite opposite - the sooner cells began budding after irradiation, the greater was their survival. These observations suggest that the process of cell recovery from potentially lethal radiation damage could occur on the nutrient medium and results in the increase of cell resistance to ionizing radiation. It is known that keeping irradiated cells in sub-optimal environment condition resulted in an increase of cell survival. It has been suggested (2) this effect is due to DNA repair improvement in this condition and several papers were published in this regard. The data presented here indicate the effect may be mainly due to the enhanced duration of cell recovery. The main conclusion to be drawn from these experiments is that the process of LHR takes place on nutrient media during the delay of the first postirradiation division. The insight obtained may be of great importance for understanding the discrimination observed in radiosensitivity determination in various investigations $(4,5,14)$.

Comparing survival curves for S. ellipsoideus diploid yeast cells obtained in experiments with wild type strain Megry 139-B capable of the LHR and its respiratory-deficient strain Megry 39-2 incapable of such kind of recovery, it was concluded that LHR occurring on the nutrient media before the fixation of radiation damage after the ending of the first postirradiation division results in the decrease of cell radiosensitivity by a factor of 1.42 . Further 
confirmation of this factor was obtained by means of the calculation of the expected survival curve of Megry 139-B cells if they would not be able to the LHR on the nutrient media. It was calculated by means of a mathematical approach developed before (12). These data allow us to formulate several conclusions. The coincidence of exponential parts of calculated and experimental survival curves for Megry 39-2 means that the increased radiosensitivity of this strain is mainly due to the loss of cell ability to the LHR. Further, it means that our previous assumption (12) concerning the equality of the rate of LHR in the water and on the nutrient medium is fairly plausible. Finally, it means that we managed to get a method for calculating the contribution of LHR taking place on nutrient media in the viability of irradiated cells.

We applied this method to interpret cell survival and recovery kinetics resulted from simultaneous action of high temperatures with either $\gamma$-rays $\left({ }^{60} \mathrm{Co}\right)$ or UV light $(254 \mathrm{~nm})$ studied in diploid yeast cells capable of the LHR. It was shown the increase in the exposure temperature resulted in a considerable increase in cell sensitivity to ionizing radiation and UV light, as illustrated by a pronounced increase in the slope and the decrease in the extrapolation number. The interaction of heat with ionizing radiation or UV light was synergistic, i.e. the net effect of the two kinds of these agents together is greater than the sum of the logarithms of their independent effects. The dashed lines presented in Figs. 2, 3 reflect the expected survival curves for yeast cells if they would not be able to the LHR on the nutrient medium before the fixation of potentially lethal damage after the first postirradiation division. The major point to be inferred from these data is that the observed increase in cell sensitivity to simultaneous treatment of hyperthermia with ionizing radiation or UV light is much greater than that expected due to the suppression of the LHR. Hence, the complete inhibition of LHR may serve as an indicator of significant inhibition of other dark repair systems and significantly increase in cell sensitivity. These data also suggest that more is involved in the increased cell radiosensitivity than just inhibition of the LHR.
Effect can be interpreted as being due to either interference with other repair processes of potential lethal damage, or enhanced expression of radiation damage. This expression may be related with synergistic interaction of heat with ionizing radiation (15) and UV light (16).

A quantitative approach describing the LHR $(11,12)$ was applied to estimate quantitatively both the irreversible component of radiation damage expressed as the fraction of initial radiation dose which cells are incapable to recover and the recovery constant which define the probability of recovering per time unit after the combined action of hyperthermia with either ionizing radiation $(4,15)$ or UV light $(4,16)$. It was shown that the synergistic interaction of heat with ionizing radiation or UV light is due to increase in the irreversible component with increasing thermal load while recovery constant was equal about of 0.07-0.09 $\mathrm{h}^{-1}$ and was independent of conditions of treatment, i.e. about $7-9 \%$ of the residual reparable damage is recovered every hour. Equality of recovery constants after irradiation with gamma rays or ultraviolet light applied alone or combined with heat has led to the identity of the dashed curves presented in figures 2 and 3.

It was of interest to test whether or not this pattern holds for other interacting agent. The impairment of cell ability to recover from radiation damage would be of great relevance in cancer treatment. Hyperthermia as well as a lot of chemicals have been found to be recovery inhibitors $(2,3,9,18)$. Although the means by which these agents sensitize cells to ionizing radiation are not completely understood, it is generally agreed that their efficacy is expressed as both a retarded recovery rate and a lesser volume of recovery. Kumar et al. published dose-survival curves and kinetics of LHR of Chinese hamster V79 cells (18) exposed to X-rays alone or in combination with various chemical compounds (pyruvate, novobiocin, lactate, nalidixic acid, 3aminobenzamide). The drugs were added $1 \mathrm{~h}$ before irradiation, presented during irradiation and LHR. Our estimation of recovery constant (5) based on these publication showed that it was equal of $0.1-0.15 \mathrm{~h}^{-1}$. This value is somewhat higher than for yeast cells. That is why the

Int. J. Radiat. Res., Vol. 15 No. 2, April 2017 
inhibition of the LHR on nutrient media would result in increase of mammalian cell radiosensitivity by means of DMF $=1.4-1.7$. The combined action of ionizing radiation with chemical radiosensitizers increased radiosensitivity of cells by a factor of $2.1-2.5$, i.e. the sensitization was significantly great than that expected after the LHR inhibition alone. These data and numerous other results $(1,5,10,18$, 19) indicate that inhibition of cell ability to LHR from potentially lethal radiation damage in many cases may serve as an indicator of the significant increase in cell sensitivity to damaging agents due to inhibition of other dark repair systems or enhanced expression of primary radiation damage. However, as it was demonstrated in this paper, the stated rule is not universal. It was shown that the cells holding in the solution of cisplatin at a concentration of $0.002 \mathrm{mg} / \mathrm{ml}$ displayed a significant inhibition of the LHR and some increase in radiation sensitivity that correspond to the expected value if there is no LHR on nutrient medium. The further increase in cisplatin concentration resulted in almost full inhibition of LHR while the further increase in cell radiosensitivity was not observed. This means that the inhibition of cell LHR may not always serve as an indicator of the significant increase in cell sensitivity to damaging agents.

\section{ACKNOWLEDGEMENTS}

This study has been carried out under the financial support from the Russian Federation President Grant, Russian Humanitarian Science Foundation and the Government of the Kaluga Region (project number 15-16-40010) and Russian Fond of Fundamental Science (project number 16-34-0077016).

\section{Conflicts of interest: Declared none.}

\section{REFERENCES}

1. Hall EJ and Giaccia AJ (2006) Radiobiology for the Radiologist. Philadelphia: Lippincott Williams \& Wilkins.

Int. J. Radiat. Res., Vol. 15 No. 2, April 2017
2. Saha GB (2006) Physics and Radiobiology of Nuclear Medicine. Third Edition. Springer.

3. Buhtoiarov IN, Sondel PM, Wigginton JM, Buhtoiarova TN, Yanke EM, Mahvi DA, et al. (2011) Anti-tumour synergy of cytotoxic chemotherapy and anti-CD40 plus CpG-ODN immunotherapy through repolarization of tumourassociated macrophages. Immunology, 132: 226-239.

4. Petin VG, Zhurakovskaya GP, Komarova LN (2012) Radiobiological basis of synergistic interaction in biosphere. Moscow: GEOS.

5. Petin VG and Kim JK (2014) Synergistic Interaction and Cell Responses to Environmental Factors. New York: Nova Sciences Publishers.

6. Joiner M and van der Kogel A (2009) Basic Clinical Radiobiology. Edward Arnold. London.

7. El-Awady RA, Dikomey E, Dahm-Daphi J (2001) Heat effects on DNA repair after ionizing radiation: hyperthermia commonly increases the number of non-repaired doublestrand breaks and structural rearrangements. Nucleic Acids Res, 29: 1960-1966.

8. Little JB and Williams JR (2011) Effects of ionizing radiation on mammalian cells. In: Comprehensive physiology. Supplement 26. Handbook of physiology. Reactions to environmental agents. Pp:127-155.

9. Streffer C and Herrmann T (2012) A century of development in radiation biology. Basic principles of targeted and efficient radiotherapy. Strahlenther Onkol, 188 (S3): 231-244.

10. Petin VG, Kim JK, Evstratova ES, Komarova LN (2013) Quantitative estimation of recovery parameters after combined action of ionizing radiation and chemical agents. Int $J$ Radiat Res, 11: 17-27.

11. Korogodin VI (1993) The study of post-irradiation recovery of yeast: the 'prermolecular period'. Mutat Res, 289: 1726.

12. Kapultsevich YuG, Petin VG, Korogodina YuV, Korogodin VI (1974) Evaluation of postradiation recovery contribution in yeast cell radiosensitivity. Proc. USSR Academy. Biological Series, 4: 549-562.

13. Urano M., Kahn J., Majima H., Gerweck L.E. (1990) The cytotoxic effect of cis-diamminedichloroplatinum (II) on cultured Chinese hamster ovary cells at elevated temperatures: Arrhenius plot analysis. Int J Hyperthermia, 6: 581590.

14. Chapman JR, Taylor MRG, Boulton SJ (2012) Playing the end game: DNA double-strand break repair pathway choice. Molecular cell, 47: 497-510.

15. Petin VG and Kim JK (2004) Survival and recovery of yeast cells after combined treatments with ionizing radiation and heat. Radiat. Res, 161: 56-63.

16. Kim JK, Petin VG, Tkhabisimova MD (2004) Survival and recovery of yeast cells after simultaneous treatment of UV light radiation and heat. Photochem Photobiol, 79: 349355.

17. Petin VG, Evstratova ES, Kim JK (2014) Radiosensitivity, liquid-holding recovery and relative biological effectiveness of densely-ionizing radiation after repeated irradiation of yeast cells, Mutat Res, 771: 37-42. 
18. Kumar A, Kiefer J, Schneider E, Crompton NEA (1985) Inhibition of recovery from potentially lethal damage by chemicals in Chinese hamster V79 A cells. Radiat Environ Biophys, 24 (2): 89-98.

19. Petin VG, Zhurakovskaya GP, Komarova LN (1997) Fluence rate as a determinant of synergistic interaction of simultaneous action of UV-light and mild heat in Saccharomyces cerevisiae. J Photochem Photobiol B: Biol, 38: 123-128.

20. Castellani A (2012) Research in photobiology. Springer Science \& Business Media. United States.

21. Dikomey E and Jung $H$ (1995) Correlation between thermal radiosensitization and slowly rejoined DNA strand breaks in CHO cells. Int J Radiat Biol, 68: 227-233. 
